\title{
Impact of residual carbon on two-dimensional electron gas properties in $\mathrm{Al}_{\mathrm{x}} \mathrm{Ga}_{1-\mathrm{x}} \mathrm{N} / \mathrm{GaN}$ heterostructure
}

\author{
Jr-Tai Chen, Urban Forsberg and Erik Janzén
}

\section{Linköping University Post Print}

\section{Tweet}

N.B.: When citing this work, cite the original article.

Original Publication:

Jr-Tai Chen, Urban Forsberg and Erik Janzén, Impact of residual carbon on two-dimensional electron gas properties in $\mathrm{Al}_{\mathrm{x}} \mathrm{Ga}_{1-\mathrm{x}} \mathrm{N} / \mathrm{GaN}$ heterostructure, 2013, Applied Physics Letters, (102), 19, 193506.

http://dx.doi.org/10.1063/1.4804600

Copyright: American Institute of Physics (AIP)

http://www.aip.org/

Postprint available at: Linköping University Electronic Press

http://urn.kb.se/resolve?urn=urn:nbn:se:liu:diva-96138 


\title{
Impact of residual carbon on two-dimensional electron gas properties in $\mathrm{Al}_{\mathrm{x}} \mathrm{Ga}_{1-\mathrm{x}} \mathrm{N} / \mathrm{GaN}$ heterostructure
}

\author{
Jr-Tai Chen, ${ }^{\text {a) }}$ Urban Forsberg, and Erik Janzén \\ Department of Physics, Chemistry, and Biology (IFM), Linköping University, SE 58183 Linköping, Sweden
}

(Received 26 March 2013; accepted 21 April 2013; published online 14 May 2013)

\begin{abstract}
High tuneability of residual carbon doping is developed in a hot-wall metalorganic chemical vapor deposition reactor. Two orders of temperature-tuned carbon concentration, from $\sim 2 \times 10^{18} \mathrm{~cm}^{-3}$ down to $\sim 1 \times 10^{16} \mathrm{~cm}^{-3}$, can be effectively controlled in the growth of the GaN buffer layer. Excellent uniformity of two-dimensional electron gas (2DEG) properties in $\mathrm{Al}_{\mathrm{x}} \mathrm{Ga}_{1-\mathrm{x}} \mathrm{N} / \mathrm{AlN} / \mathrm{GaN}$ heterostructure with very high average carrier density and mobility, $1.1 \times 10^{13} \mathrm{~cm}^{-2}$ and $2035 \mathrm{~cm} / \mathrm{V} \cdot \mathrm{s}$, respectively, over 3" semi-insulating $\mathrm{SiC}$ substrate is realized with the temperature-tuned carbon doping scheme. Reduction of carbon concentration is evidenced as a key to achieve high 2DEG carrier density and mobility. (C) 2013 AIP Publishing LLC.
\end{abstract}

[http://dx.doi.org/10.1063/1.4804600]

Over the past decade, the excellent performance of GaNbased high electron mobility transistors (HEMTs) in highpower and high-frequency electronic devices has been demonstrated. ${ }^{1-3}$ However, the device reliability is still an issue. ${ }^{4}$ The electrical property of GaN buffer layer (GaN BL) in the HEMT structure is one of the critical parameters that will influence the final device reliability. ${ }^{4-6}$ Firstly, the GaN $\mathrm{BL}$ has to be semi-insulating (SI) to prevent unwanted current paths underneath the two-dimensional electron gas (2DEG) channel and also to obtain high breakdown voltage with low leakage current. One effective way to achieve this is to introduce acceptor-like impurities, like iron ${ }^{7}$ or carbon, ${ }^{8-10}$ during growth of the GaN BL; however, iron doping has a memory effect rendering doping profile difficult to control. Secondly, in order to alleviate the trapping effect that causes failure of device characteristics, known as current collapse, the level of acceptor-like impurities in the vicinity of 2DEG channel should be minimized. ${ }^{5,6,11}$ Apparently, these two requirements for the GaN BL are in conflict with each other. Therefore, the level of acceptor-like impurities in the GaN BL needs to be carefully defined and optimized.

In the III-nitride metalorganic chemical vapor deposition (MOCVD) growth process, carbon impurity commonly exists in the materials due to the use of metal-organic precursors. Another contribution of carbon may come from the TaC coating of the susceptor and the graphite-made insulation used around the susceptor. ${ }^{12}$ During growth, these two components could release carbon that will add to the total carbon vapor pressure in the reactor. Hence, the residual carbon concentration in the material is determined by the reactor design and the process parameters that are used during growth. Early studies show that the growth temperature and the V/III ratio influence the carbon incorporation, but only to a limited extent. ${ }^{13,14}$ Growth pressure appears to be a more effective way to swing the incorporation of carbon. ${ }^{9,10}$ However, one can expect that, as the growth pressure is varied, many other growth parameters are correspondingly changed at the same

\footnotetext{
${ }^{\text {a) }}$ Author to whom correspondence should be addressed. Electronic mail: jrche@ifm.liu.se
}

time, like wafer temperature, deposition profile, and effective $\mathrm{V} / \mathrm{III}$ ratio. This renders it difficult in establishing a good process for growth of high-uniformity epi-layers on large wafer area.

On the other hand, since carbon incorporation inevitably takes place in the growth process, it is important to know how low the carbon concentration in the GaN BL needs to be to sufficiently reduce its trapping effect in the HEMTs device. However, this information is still lacking in the literature.

In this work, we demonstrate the development of high tuneability of residual carbon doping in a hot-wall MOCVD reactor. This capability provides the opportunity (i) to systematically study the effect of growth temperature on the structure quality of $\mathrm{AlGaN} / \mathrm{GaN}$ HEMTs growth and the subsequent impact of the temperature-tuned carbon levels on the 2DEG properties, (ii) to optimize the carbon profile in the GaN buffer layer, and to apply the optimized carbon doping structure in GaN HEMT structure grown on 3" SI SIC wafers.

Detail of the hot-wall MOCVD growth system has been presented elsewhere. ${ }^{12,15}$ The growth was initiated with an AlN nucleation layer $\left(100 \mathrm{~nm}\right.$ thick) grown at $1100^{\circ} \mathrm{C}$ after $\mathrm{SiC}$ substrate surface pretreatment in $\mathrm{H}_{2}$ ambient at $1200^{\circ} \mathrm{C}$ for $15 \mathrm{~min}$, followed by $\mathrm{GaN}$ growth or $\mathrm{AlGaN} / \mathrm{GaN}$ HEMT structure growth. Two samples of GaN layers on $\mathrm{AlN} / \mathrm{SiC}$ system were grown under a constant $\mathrm{NH}_{3}$ flow $(21 / \mathrm{min})$, denoted S1 and S2, to study the residual impurity incorporation in $\mathrm{GaN}$ as a function of its growth conditions. Sample S1 contains six layers of GaN, each $300 \mathrm{~nm}$ thick, grown at different growth temperatures, ranging from 980 to $1080^{\circ} \mathrm{C}$ in step of $20^{\circ}$ with a constant TMGa flow of $40 \mathrm{ml} / \mathrm{min}$. The GaN growth rate, GR, increases slightly with growth temperature, within the investigated temperature window, from $\sim 0.7 \mu \mathrm{m} / \mathrm{h}$ to $\sim 0.8 \mu \mathrm{m} / \mathrm{h}$. Sample $\mathrm{S} 2$ contains five layers of $\mathrm{GaN}$ grown at $1080^{\circ} \mathrm{C}$, each $410 \mathrm{~nm}$ thick, grown with different $\mathrm{V} / \mathrm{III}$ ratios by increasing the TMGa flow from $20 \mathrm{ml} / \mathrm{min}$ to $100 \mathrm{ml} / \mathrm{min}$, resulting in the changes of the $\mathrm{V} / \mathrm{III}$ ratio from 1325 to 265 and the GaN GR from $\sim 0.4 \mu \mathrm{m} / \mathrm{h}$ to $\sim 2 \mu \mathrm{m} / \mathrm{h}$, see Fig. 1(a). Next, a series of AlGaN/GaN HEMT structures consisting of a GaN buffer layer $(\sim 1.7 \mu \mathrm{m})$ and an $\mathrm{Al}_{0.28} \mathrm{Ga}_{0.72}$ $\mathrm{N}$ barrier layer $(24 \mathrm{~nm})$ were grown on $2 \times 2 \mathrm{~cm}^{2}$ on-axis 
(0001) SI 4H-SiC substrates to investigate the effect of carbon on 2DEG properties. Both the GaN and the $\mathrm{Al}_{0.28} \mathrm{Ga}_{0.72}$ $\mathrm{N}$ layers were grown at the same temperature. Five complete HEMT structures, denoted T1-T5, were grown in a temperature range of $1000^{\circ} \mathrm{C}-1090{ }^{\circ} \mathrm{C}$ with a constant $\mathrm{NH}_{3}(2 \mathrm{l} / \mathrm{min})$ and TMGa flow $(40 \mathrm{ml} / \mathrm{min})$ corresponding to $\mathrm{V} / \mathrm{III}$ ratio 1060 for the GaN BL growth (GR of $0.7-0.8 \mu \mathrm{m} / \mathrm{h}$ ). In addition, two more HEMT samples T6 and $\mathrm{W} 1$ were prepared with the step-profiled carbon-doped GaN buffer layers on a $2 \times 2 \mathrm{~cm}^{2}$ piece and a 3 " wafer of SI SiC substrates, respectively. The detail of which will be described later. Secondary ion mass spectrometry (SIMS) was performed on the sample $\mathrm{S} 1, \mathrm{~S} 2$, and T2. Silicon, oxygen, and carbon were monitored throughout the entire GaN epilayers. The detection limits of $\mathrm{Si}, \mathrm{O}$, and $\mathrm{C}$ are $8 \times 10^{16} \mathrm{~cm}^{-3}, 1 \times 10^{16} \mathrm{~cm}^{-3}$, and $1 \times 10^{16} \mathrm{~cm}^{-3}$, respectively, in this specific measurement.

The sample S1 was specifically designed for investigating the carbon incorporation in $\mathrm{GaN}$ as a function of growth temperature. Explicitly, carbon incorporation is highly growth-temperature controllable in our hot-wall MOVCD system, as shown in Fig. 1(b). The carbon profile follows exactly the temperature changes. This can be evidenced by the bumps of carbon concentration appearing in the SIMS profile as a result of the temperature dips when the temperature was being stabilized. The concentration of carbon in GaN is remarkably decreased with increasing growth temperature, from to $\sim 2.0 \times 10^{18} \mathrm{~cm}^{-3}$ at $980^{\circ} \mathrm{C}$ to $1.8 \times 10^{16} \mathrm{~cm}^{-3}$ at $1080^{\circ} \mathrm{C}$. This can be explained by the model that Parish et al. proposed ${ }^{13}$ that carbon removal from the surface is facilitated by conversion of methyl groups from TMGa into methane with adsorbed hydrogen. At high temperature, more adsorbed hydrogen is available from the $\mathrm{NH}_{3}$ and $\mathrm{H}_{2}$ pyrolysis. With increasing temperature, the availability of $\mathrm{H}$ atoms pyrolysed from the $\mathrm{NH}_{3}$ and process gas $\mathrm{H}_{2}$ will eventually saturate. This may determine how low carbon incorporation can be obtained in the process. Thanks to the high precursor cracking efficiency in hot-wall MOCVD, ${ }^{15}$ this renders remarkably large carbon tuneability in $\mathrm{GaN}$ growth by more than 2 orders over a temperature range of $100^{\circ} \mathrm{C}$. Besides, in the sample S1, the silicon concentration in GaN is below the SIMS detection (a)
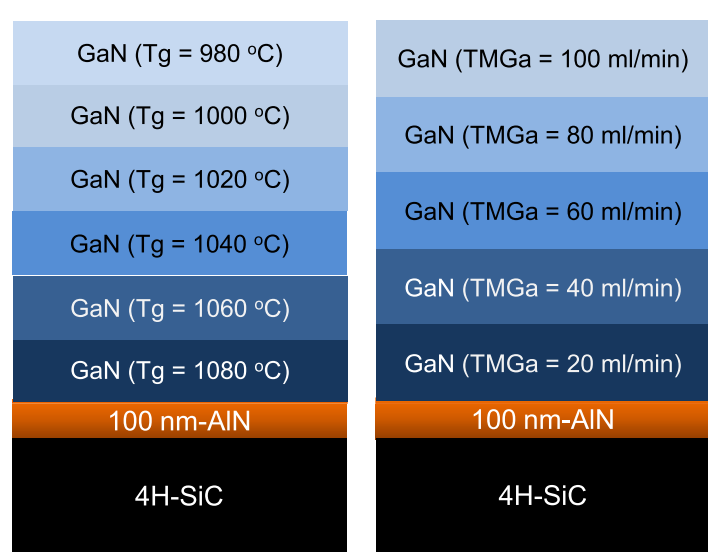

(c)

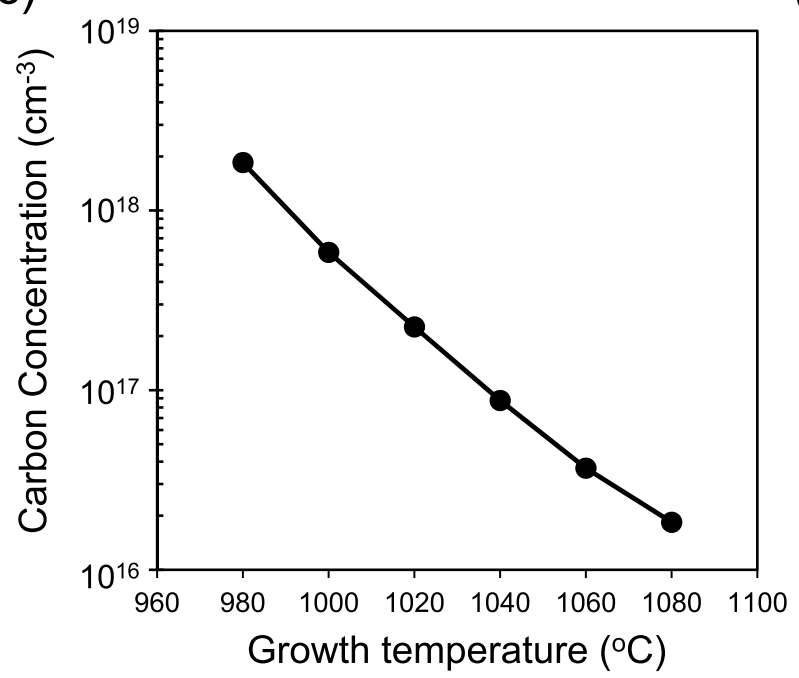

(b)
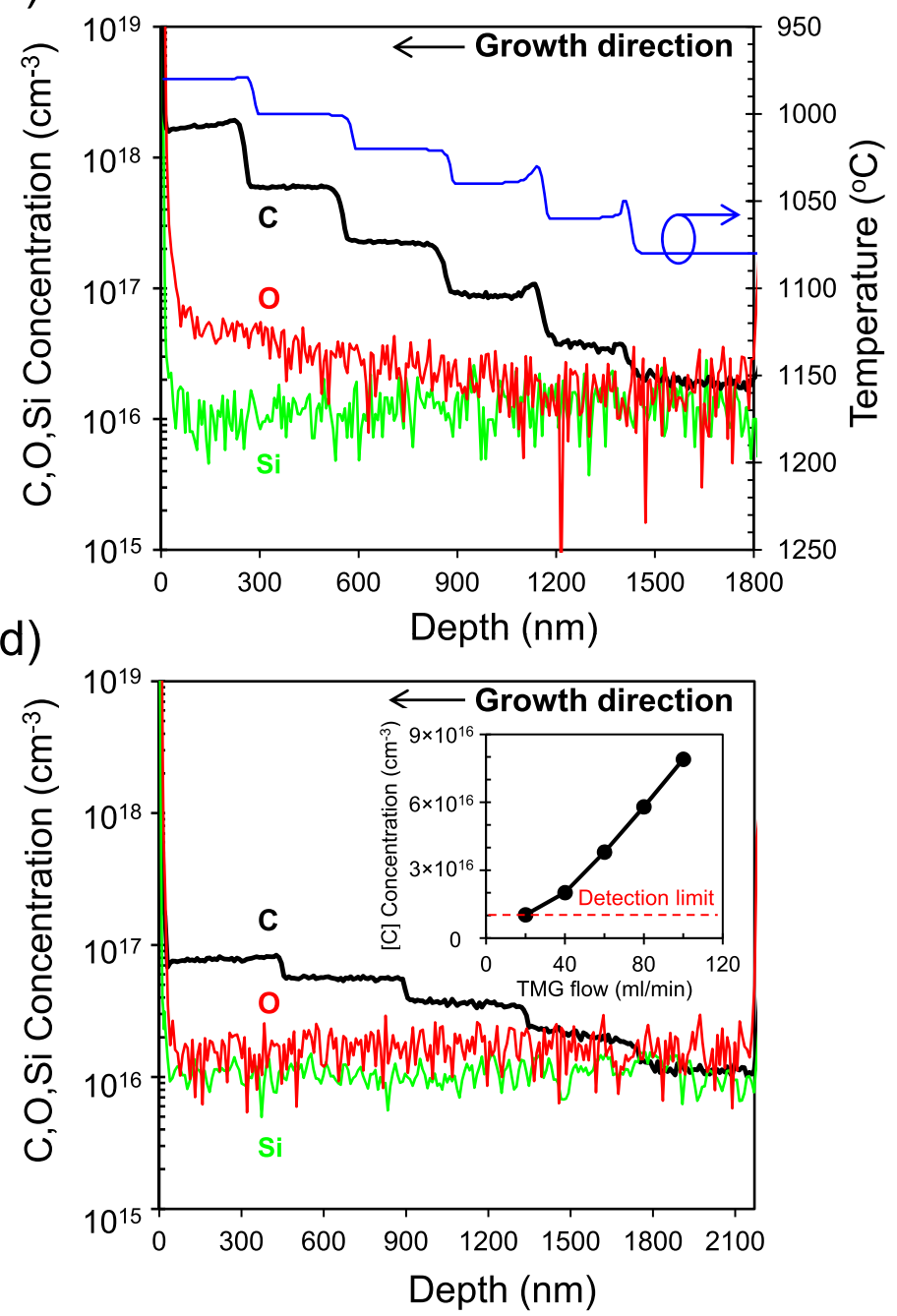

FIG. 1. (a) Schematic cross sections of the growth structures of the samples S1 and S2. (b) Impurity concentrations of as a function of depth in GaN layers controlled by growth temperature. In Fig. 1(b), the growth temperature, as monitored by a pyrometer, is also shown. The carbon concentration versus growth temperature is plotted in Fig. 1(c). (d) Impurity concentrations as a function of depth in GaN layers controlled by TMGa flow, and an inset plotting carbon concentration versus TMGa flow. The surface is located at $0 \mathrm{~nm}$. 
TABLE I. Summary of the results of the structural characterizations of the samples T1-T5.

\begin{tabular}{|c|c|c|c|c|}
\hline \multirow[t]{2}{*}{ Sample } & \multirow{2}{*}{$\frac{\text { Growth }}{\text { Temperature }}$} & \multirow{2}{*}{ 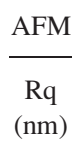 } & \multicolumn{2}{|c|}{ XRD } \\
\hline & & & $\begin{array}{c}\mathrm{GaN}(002) \mathrm{FWHM} \\
(\operatorname{arcsec})\end{array}$ & $\begin{array}{c}\mathrm{GaN}(105) \mathrm{FWHM} \\
(\operatorname{arc~sec})\end{array}$ \\
\hline $\mathrm{T} 1$ & 1000 & 0.274 & 289 & 191 \\
\hline $\mathrm{T} 2$ & 1020 & 0.273 & 206 & 181 \\
\hline T3 & 1050 & 0.230 & 214 & 156 \\
\hline $\mathrm{T} 4$ & 1080 & 0.183 & 205 & 150 \\
\hline $\mathrm{T} 5$ & 1090 & 2.400 & 202 & 177 \\
\hline
\end{tabular}

limit throughout the entire range of investigated growth temperature and only very low $\mathrm{O}$ concentration is detectable at the side of low growth temperature regime.

To add more information to the carbon tuneability in GaN growth, the sample $\mathrm{S} 2$ was grown to investigate the effect of TMGa flow rate. As shown in Fig. 1(d), the carbon concentration in the GaN layers increases proportionally with TMGa flow rate, due to increased methyl groups from the precursor, which is consistent with our previous study. ${ }^{16}$ This can prove that the availability of adsorbed $\mathrm{H}$ is the limiting factor in the process of carbon removal from incorporation. The sensitivity of carbon incorporation versus TMGa flow is also very pronounced. A change of TMGa flow from 20 to $100 \mathrm{ml} / \mathrm{min}$ results in an increase of carbon incorporation by almost 8 times. The concentrations of silicon and oxygen are under the detection limit at the given growth temperature, which is consistent with the previous SIMS result.

Additionally, such wide-range carbon tuneability allows us to systematically study the carbon effect on 2DEG properties in HEMT structure and to optimize the carbon profile in the GaN buffer layer. Table I summarizes the results of the structural characterizations of the HEMTs samples grown in the series of $\mathrm{T} 1-\mathrm{T} 5$.

The surface morphology and root-mean-square roughness $(\mathrm{Rq})$ of the AlGaN/GaN HEMT structures were analyzed by atomic force microscopy (AFM) over a $3 \times 3 \mu \mathrm{m}^{2}$ area. The AFM images of the AlGaN/GaN heterostructures shown in the Fig. 2 all exhibit step-flow growth and the terrace size gradually increases with increased growth temperature resulting in smoother surface. This is understandable since the diffusion length of adatom surface migration is enhanced at higher growth temperature. Nevertheless, some morphological defects appear when the growth was carried out at $1090^{\circ} \mathrm{C}$, indicating that the high-temperature limit of a stable growth regime for $\mathrm{AlGaN} / \mathrm{GaN}$ heterostructures is reached.

High-resolution $\mathrm{x}$-ray diffraction (XRD) measurements, including $\theta-2 \theta$ scans, rocking curve analysis, and reciprocal space maps, were carried out to characterize the crystalline quality of all epi-layers and to determine the composition and the thickness of the AlGaN layers. In the analysis of $x$-ray rocking curves of the GaN layers, the values of the full width of half maximum (FWHM) of the (002) and (105) peaks reveal that the growth temperature for $\mathrm{GaN}$ layers grown in this temperature regime does not have any remarkable impact on its crystalline quality. The (002) and (105) GaN peaks improve gradually up to $1080^{\circ} \mathrm{C}$, which indicates that the dislocation density is decreased with increased growth temperature. However, at the growth temperature of $1090^{\circ} \mathrm{C}$, the (105) GaN peak starts to broaden again. This shows a good agreement with the observation of rapid deterioration of the surface morphology as seen from AFM. The composition and thickness of $\mathrm{AlGaN}$ barrier layers grown in this range are shown stably constant around $28 \%$ and $24 \mathrm{~nm}$, respectively. And the reciprocal space maps of the samples T1-T5 indicate that all $\mathrm{AlGaN}$ barrier layers were pseudo-morphically grown on $\mathrm{GaN}$ buffer layers. Therefore, we can conclude that a wide growth window, extending over a temperature range of $80^{\circ}$, is permitted in our process for the growth of high structuralquality $\mathrm{AlGaN} / \mathrm{GaN}$ HEMT structure.

The impact of growth temperature on the 2DEG properties is substantial. The 2DEG carrier density extracted from the mercury-probe capacitance-voltage (CV) measurement shows strong growth-temperature dependence, varying almost threefold from $3.3 \times 10^{12} \mathrm{~cm}^{-2}$ to $8.8 \times 10^{12} \mathrm{~cm}^{-2}$ for the growth temperature at $1000^{\circ} \mathrm{C}$ to $1090^{\circ} \mathrm{C}$, respectively, as shown in Fig. 3. Contactless Lehighton (LEI 1610) mobility measurement system with a probing area $\sim 3.5 \mathrm{~cm}^{2}$ was performed to measure the 2DEG mobility. We found that the 2DEG mobility increases significantly from $218 \mathrm{~cm}^{2} / \mathrm{V} \cdot \mathrm{s}$ to $1535 \mathrm{~cm}^{2} / \mathrm{V} \cdot \mathrm{s}$ when the growth temperature increases from $1000^{\circ} \mathrm{C}$ to $1080^{\circ} \mathrm{C}$, and then drops at the growth temperature of $1090^{\circ} \mathrm{C}$, which can be correlated with the deterioration of morphology and crystalline quality. Thus, with increased growth temperature in the permitted growth window, the 2DEG carrier density and the 2DEG mobility both increase and reach a maximum of $\sim 8.2 \times 10^{12} \mathrm{~cm}^{-2}$ and $1535 \mathrm{~cm}^{2} / \mathrm{V} \cdot \mathrm{s}$, respectively, at $1080^{\circ} \mathrm{C}$. As evidenced in Fig. 1(b), the growth temperature is hugely responsible for the amount of carbon incorporation, so that such large change in the 2DEG density
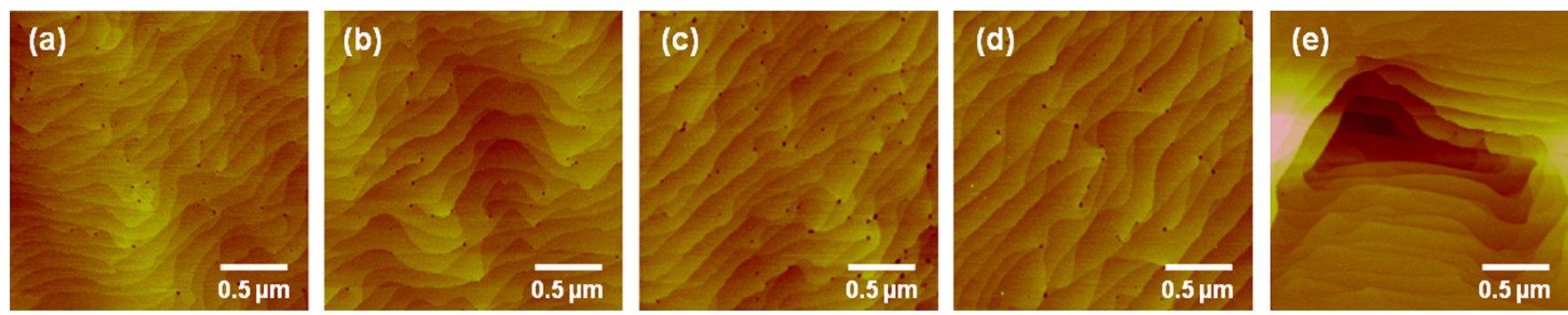

FIG. 2. AFM images of the $\mathrm{AlGaN} / \mathrm{GaN}$ heterostructures grown at (a) $1000^{\circ} \mathrm{C}$ for the sample $\mathrm{T} 1$, (b) $1020^{\circ} \mathrm{C}$ for $\mathrm{T} 2$, (c) $1050^{\circ} \mathrm{C}$ for $\mathrm{T} 3$, (d) $1080^{\circ} \mathrm{C}$ for $\mathrm{T} 4$, and (e) $1090^{\circ} \mathrm{C}$ for $\mathrm{T} 5$. 


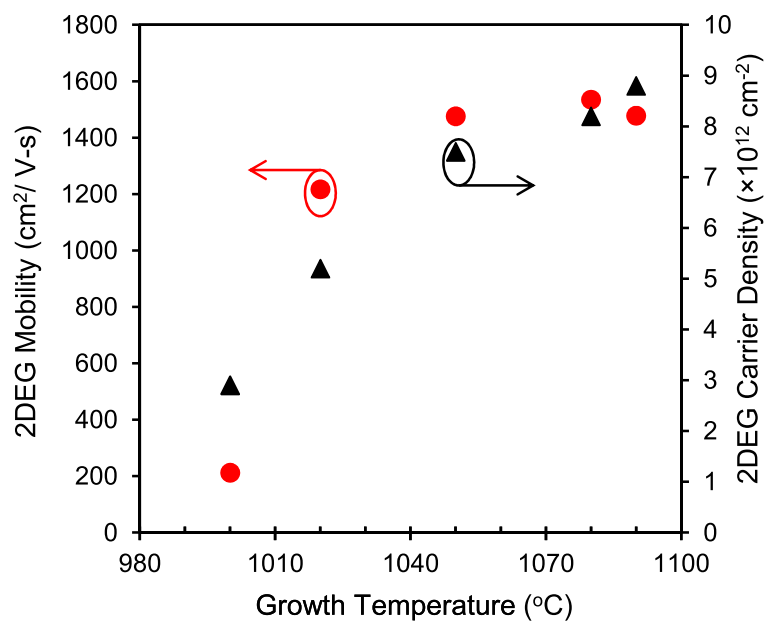

FIG. 3. 2DEG mobility and carrier density in the AlGaN/GaN heterostructures as a function of growth temperature.

as a function of growth temperature apparently is associated with carbon concentrations in GaN BL. This observation is consistent with the previous study done by Klein et al. that the reduction of 2DEG carrier density is attributed to the trapping effect caused by carbon-related defect. ${ }^{11,17}$ One should also note that the silicon and oxygen concentrations in the investigated samples are below the carbon concentrations, except in the sample T5 where the carbon concentration is likely lowered down to a level close to those of silicon and oxygen as the growth temperature is elevated above $1080^{\circ} \mathrm{C}$ (Fig. 1(b)). In this case, non-compensated silicon and oxygen impurities may add some extra carriers. This might be the reason that the 2DEG carrier density of the sample T5 does not closely follow the trend of 2DEG carrier density as a function of growth temperature observed in this series. The 2DEG carrier densities of the samples T4 and T5 are very close to the values calculated theoretically, ${ }^{18}$ indicating that the trapping effect is significantly reduced as carbon concentration is below $\sim 5 \times 10^{16} \mathrm{~cm}^{-3}$ in the GaN BL. On the other hand, concerning the trend of the 2DEG mobility as a function of growth temperature shown in Fig. 3, we found that 2DEG mobility dramatically increases from 218 to $1217 \mathrm{~cm}^{2} / \mathrm{V} \cdot \mathrm{s}$ for the growth done at $1000^{\circ} \mathrm{C}$ and $1020^{\circ} \mathrm{C}$, respectively. The significant increase of mobility cannot simply be explained by the improved structure quality alone, since both samples have similar surface roughness and the dislocation densities in these two samples are of the same order. We believe that it is associated with the reduction of carbon concentration, which in turn mitigates trapping effect and ionized impurity scattering. ${ }^{19,20}$ The increase in the growth temperature between these two samples $\mathrm{T} 1$ and $\mathrm{T} 2$ corresponds to the reduction of carbon from $5.8 \times 10^{17} \mathrm{~cm}^{-3}$ to $2.2 \times 10^{17} \mathrm{~cm}^{-3}$ according to the carbon concentrations plotted in Fig. 1(c). To be careful with the carbon value in the GaN BL of the sample T2, a SIMS analysis was performed on it. A carbon concentration of $\sim 3 \times 10^{17} \mathrm{~cm}^{-3}$ was measured, showing that this temperaturetuned carbon doping has high reproducibility. Most importantly, this result reveals that the carbon concentration needs to be reduced below $\sim 1 \times 10^{17} \mathrm{~cm}^{-3}$ in the vicinity of the 2DEG channel in order to achieve high 2DEG mobility. As the growth temperature is further raised, the 2DEG mobility continues to increase and then saturates at $1535 \mathrm{~cm}^{2} / \mathrm{V} \cdot \mathrm{s}$. Thus, we correlate the improvement of the 2DEG mobility with further reduced carbon concentration and improved structural quality.

With the aim to combine the features of high resistivity and low trapping effect in a GaN BL, a step-like carbon profile in the GaN buffer layer is needed. Therefore, the sample T6 was designed with a $1.6 \mu$ m-thick high-carbon $\mathrm{GaN}$ buffer layer, grown at $1000^{\circ} \mathrm{C}$ with a TMGa flow of $65 \mathrm{ml} / \mathrm{min}$ (GR of $1.05 \mu \mathrm{m} / \mathrm{h}$ ), followed by a $100 \mathrm{~nm}$-thin low-carbon spacer layer, grown at $1080^{\circ} \mathrm{C}$ with a TMGa flow of $25 \mathrm{ml} / \mathrm{min}$ (GR of $0.5 \mu \mathrm{m} / \mathrm{h}$ ), adjacent to the AlGaN barrier. The growth temperature was controlled to ramp from 1000 to $1080^{\circ} \mathrm{C}$ for the growth of these two respective GaN layers and continued by AlGaN barrier layer growth. The $\mathrm{NH}_{3}$ flow (21/min) was kept constant for the entire growth. This $\mathrm{Al}_{0.28} \mathrm{Ga}_{0.72} \mathrm{~N}(24 \mathrm{~nm}) /$ GaN HEMTs sample with the temperature-tuned carbon profile in the GaN layer leads to $2 \mathrm{DEG}$ carrier density of $8.24 \times 10^{12} \mathrm{~cm}^{-2}$, which is consistent with the result of the sample T4, and a high 2DEG mobility of $1650 \mathrm{~cm}^{2} / \mathrm{V} \cdot \mathrm{s}$. We attribute the high 2DEG mobility to (i) alleviated trapping effect resulting from low carbon-related defects and (ii) better $2 \mathrm{DEG}$ confinement formed by a step-profiled carbon in GaN buffer layer. ${ }^{21}$ Furthermore, the crystalline quality and surface roughness of this sample are similar with those of the sample T1, since both samples' GaN BLs were grown at $1000^{\circ} \mathrm{C}$, proving that the 2DEG mobility of the sample T1 is not limited by dislocation scattering and interface roughness scattering, but the carbon-related trapping effect and impurity scattering.

The optimized carbon profile obtained in the GaN BL of the sample T6 was applied to the epitaxial growth of $\mathrm{GaN}$ HEMT structure on a 3"-SI SiC wafer to test growth uniformity (the sample W1). The map of sheet resistance (Rs), ${ }^{22}$ determined by a contactless eddy-current technique, with 17 spots measured from the center radically to the edge throughout the 3" epi-wafer of $\mathrm{Al}_{0.25} \mathrm{Ga}_{0.75} \mathrm{~N}(19 \mathrm{~nm}) / \mathrm{AlN}(1 \mathrm{~nm}) /$ GaN HEMTs structure shows low Rs of $279 \Omega /$ sq with excellent uniformity of sigma/mean $=0.69 \%$ and very high average carrier density and mobility, $1.1 \times 10^{13} \mathrm{~cm}^{-2}$ and $2035 \mathrm{~cm}^{2} / \mathrm{V} \cdot \mathrm{s}$, respectively, demonstrating that such a wide range temperature-tuned growth process is suitably realized in the hot-wall MOCVD reactor with the inherent advantage of lateral and vertical temperature homogeneity.

In conclusion, by means of controlling growth temperature and V/III ratio, we demonstrate that high carbon tuneability can be realized in the hot-wall MOCVD. The impact of carbon impurity on 2DEG properties was found substantial. Reducing carbon concentration in the vicinity of the 2DEG channel can significantly enhance 2DEG properties. Finally, the AlGaN/AlN/GaN HEMT structure with the temperature-tuned step-like carbon profile in GaN buffer shows outstanding uniformity of Rs distribution over the 3" epi-wafer on SI-SiC substrate. These results are very promising for development of trap-free 2DEG GaN spacer layer and highly resistive GaN buffer layer in HEMT structure.

The authors would like to thank Dr. A. KakanakovaGeorgieva and Dr. V. Darakchieva for some very fruitful discussions and acknowledge the funding support from the Swedish Foundation for Strategic Research (Dr. Niklas 
Rorsman) and the European project of High Quality European GaN-Wafer on SiC Substrates for Space Applications (EuSiC).

${ }^{1}$ C. Poblenz, A. L. Corrion, F. Recht, C. S. Suh, R. Chu, L. Shen, J. S. Speck, and U. K. Mishra, IEEE Electron Device Lett. 28, 945 (2007).

${ }^{2}$ J. G. Felbinger, M. Fagerlind, O. Axelsson, N. Rorsman, X. Gao, S. Guo, W. J. Schaff, and L. F. Eastman, IEEE Electron Device Lett. 32, 889 (2011).

${ }^{3}$ D. S. Lee, X. Gao, S. Guo, D. Kopp, P. Fay, and T. Palacios, IEEE Electron Device Lett. 32, 1525 (2011).

${ }^{4}$ G. Meneghesso, G. Verzellesi, F. Danesin, F. Rampazzo, F. Zanon, A. Tazzoli, M. Meneghini, and E. Zanoni, IEEE Trans. Device Mater. Reliab. 8, 332 (2008).

${ }^{5}$ S. C. Binari, K. Ikossi, J. A. Roussos, W. Kruppa, D. Park, H. B. Dietrich, D. D. Koleske, A. E. Wickenden, and R. L. Henry, IEEE Trans. Electron Devices 48, 465 (2001).

${ }^{6}$ M. J. Uren, J. Möreke, and M. Kuball, IEEE Trans. Electron Devices 59, 3327 (2012).

${ }^{7}$ S. Heikman, S. Keller, S. P. DenBaars, and U. K. Mishra, Appl. Phys. Lett. 81, 439 (2002).

${ }^{8}$ C. Poblenz, P. Waltereit, S. Rajan, S. Heikman, and U. K. Mishra, J. Vac. Sci. Technol. B 22, 1145 (2004).

${ }^{9}$ S. Kato, Y. Satoh, H. Sasaki, I. Masayuki, and S. Yoshida, J. Cryst. Growth 298, 831 (2007).

${ }^{10}$ F. Brunner, E. Bahat-Treidel, M. Cho, C. Netzel, O. Hilt, J. Würfl, and M. Weyers, Phys. Status Solidi C 8, 2427 (2011).
${ }^{11}$ P. B. Klein, S. C. Binari, K. Ikossi, A. E. Wickenden, D. D. Koleske, and R. L. Henry, Appl. Phys. Lett. 79, 3527 (2001).

${ }^{12}$ U. Forsberg, A. Lundskog, A. Kakanakova-Georgieva, R. Ciechonski, and E. Janzén, J. Cryst. Growth 311, 3007 (2009).

${ }^{13}$ G. Parish, S. Keller, S. P. Denbaars, and U. K. Mishra, J. Electron. Mater. 29, 15 (2000).

${ }^{14}$ D. D. Koleske, A. E. Wickenden, R. L. Henry, and M. E. Twigg, J. Cryst. Growth 242, 55 (2002).

${ }^{15}$ A. Kakanakova-Georgieva, R. R. Ciechonski, U. Forsberg, A. Lundskog, and E. Janzén, Cryst. Growth Des. 9, 880 (2009).

${ }^{16}$ A. Kakanakova-Georgieva, U. Forsberg, and E. Janzén, Phys. Status Solidi A 208, 2182 (2011).

${ }^{17}$ P. B. Klein, S. C. Binari, K. Ikossi, A. E. Wickenden, D. D. Koleske, and R. L. Henry, Electron. Lett. 37, 1550 (2001).

${ }^{18}$ O. Ambacher, J. Smart, J. R. Shealy, N. G. Weimann, K. Chu, M. Murphy, W. J. Schaff, L. F. Eastman, R. Dimitrov, L. Wittmer, M. Stutzmann, W. Rieger, and J. Hilsenbeck, J. Appl. Phys. 85, 3222 (1999).

${ }^{19}$ C. Y. Hwang, M. J. Schurman, W. E. Mayo, Y.-C. Lu, R. A. Stall, and T. Salagaj, J. Electron. Mater. 26, 243 (1997).

${ }^{20}$ D. Jena, S. Heikman, D. Green, D. Buttari, R. Coffie, H. Xing, S. Keller, S. DenBaars, J. S. Speck, and U. K. Mishra, Appl. Phys. Lett. 81, 4395 (2002).

${ }^{21}$ S. A. Chevtchenko, E. Cho, F. Brunner, E. Bahat-Treidel, and J. Würfl, Appl. Phys. Lett. 100, 223502 (2012).

${ }^{22}$ See supplementary material at http://dx.doi.org/10.1063/1.4804600 for the sheet resistance distribution of the AlGaN/AlN/GaN HEMT structure over the $3^{\prime \prime}$-SI SiC substrate with a step-like carbon profile in the GaN buffer layer. 